\title{
Ammonium Complexes of Orthoester Cryptands are Inherently Dynamic and Adaptive
}

\author{
Xiang Wang, ${ }^{a}$ Oleksandr Shyshov, ${ }^{a}$ Marko Hanževački ${ }^{\text {b,c }}$ Christof M. Jäger ${ }^{b^{*}}$ and Max von Delius ${ }^{\mathrm{a}^{*}}$ \\ a) Institute of Organic Chemistry and Advanced Materials, University of Ulm, Albert-Einstein-Allee 11, 89081 Ulm, \\ Germany
}

b) Department of Chemical and Environmental Engineering, University of Nottingham, University Park, Nottingham, NG7 2RD, United Kingdom

c) Rudjer Boskovic Institute, Bijenicka 54, 10000 Zagreb, Croatia.

\begin{abstract}
Fluxional chemical species such as bullvalene have been a valuable source of inspiration and fundamental insights into the nature of chemical bonds. A supramolecular analogue of bullvalene, i.e. a "fluxional host-guest system", in which the ensemble of a well-defined host and guest is engaged in continuous, degenerate constitutional rearrangements, is still elusive however. Here we report experimental and computational evidence for guest-induced dynamic covalent rearrangements in the ammonium complexes of self-assembled orthoester cryptands. This unique behaviour is made possible by the ammonium guest playing a dual role: it is sufficiently acidic to initiate dynamic covalent exchange reactions at the orthoester bridgeheads and as a hydrogen bond donor it acts as a supramolecular template, governing the outcome of a multitude of possible intra- and intermolecular rearrangement reactions. One particularly striking example of inherent dynamic behavior was observed in host-guest complex $\left[\mathrm{NH}_{4}^{+} \subset o-\mathrm{Me}_{2}-2.1 .1\right]$, which spontaneously rearranged into the larger and thermodynamically more stable complex $\left[\mathrm{NH}_{4}^{+} \subset o-\mathrm{Me}_{2}-2.2 .1\right]$, even though this process led to the formation of poor host $o-\mathrm{Me}_{2}-1.1 .1$ as a consequence of the excess of one subcomponent (diethyleneglycol; " 1 " in our nomenclature). These inherently adaptive host-guest networks represent a unique platform for exploring the interrelationship between kinetic and thermodynamic stability. For instance, as a result of optimal $\mathrm{NH}_{4}{ }^{+}$binding, complex $\left[\mathrm{NH}_{4}{ }^{+} \subset o-\mathrm{Me}_{2}-2.2 .1\right]$ was found to be thermodynamically stable (negligible intermolecular rearrangements over weeks), whereas computational studies indicate that the compound is far from kinetically stable (intramolecular rearrangements).
\end{abstract}

\section{INTRODUCTION}

Fluxional chemical species, defined as entities undergoing rapid degenerate rearrangements (IUPAC), ${ }^{1}$ have inspired much research and controversy over the past half-century. ${ }^{2-6}$ Bullvalene is perhaps the most widely known example of an organic molecule that, above a certain temperature, exists as a mixture of numerous, rapidly interconverting degenerate constitutional isomers (Scheme 1a; left). ${ }^{7,8}$ Examples of more recent work include the fascinating case of quasi-rotation of a cyclic $\mathrm{B}_{3}$ fragment in the $\mathrm{B}_{13}{ }^{+}$cluster (Scheme 1a; right), degenerate 1,2,6-hydride shifts in the non-classical 2-norbornyl cation $\left(\mathrm{C}_{7} \mathrm{H}_{11}{ }^{+}\right),{ }^{9}$ as well as (partially) degenerate positional dynamics in cyclic ${ }^{10}$ and linear "walking" systems. ${ }^{10-15}$ While fluxional systems are often considered scientific curiosities, of no use beyond revealing fundamental insights, Bode has recently demonstrated that the room temperature fluxionality of "shape-shifting"16-18 bullvalone derivatives provides a unique approach for establishing analytic fingerprint readouts for components of complex food products such as carbohydrates, flavanols, and sialic acids. ${ }^{19,20}$

Dynamic combinatorial chemistry ${ }^{21-25}$ makes use of reversible chemical bonds for generating complex mixtures that are typically subject to global thermodynamic control. This implies that all members of a dynamic combinatorial library (DCL) are connected through a network of, more or less, rapid equilibria. As a consequence, even in a DCL that is at equilibrium, exchange of subcomponents occurs continuously and in a degenerate fashion. However, because this exchange is generally not an intramolecular process (rearrangement), it does not represent fluxionality according to the IUPAC definition. ${ }^{1}$ Dynamic covalent bonds, e.g. imines, disulfides, hydrazones, also typically require the addition of a chemical species (e.g., acid catalyst) for inducing the transition from kinetically stable to dynamic, which is in contrast to fluxional species that must be inherently dynamic, at least above a certain temperature. 
Scheme 1. a) Prototypical fluxional systems. b) Schematic illustration of fluxional behavior of orthoester cryptate $\left[\mathrm{NH}_{4}{ }^{+} \subset \mathrm{o}-\mathrm{Me}_{2}-2.2 .1\right]$ via $\mathrm{NH}_{4}^{+}$-catalyzed ring-opened oxonium

a) Prototypical fluxional systems: bullvalene, $B_{13}{ }^{+}$

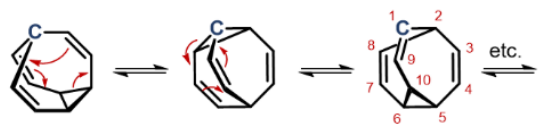

1209600 (10!/3) degenerate isomers intermediate.

b) This work: inherently dynamic host-guest system

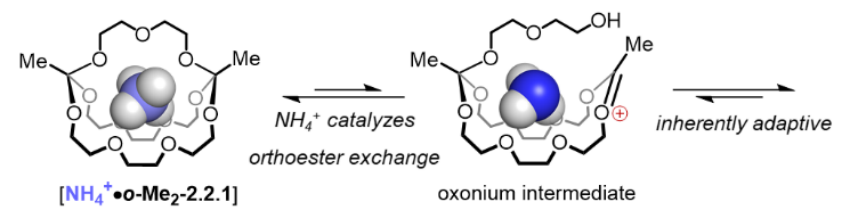

Herein, we report a dynamic covalent host-guest system that is inherently dynamic at room temperature, i.e. shows evidence for adaptive constitutional dynamic rearrangements that do not require the addition of external agents. ${ }^{26}$ The platform giving rise to this behaviour is the dynamic covalent reaction between orthoesters and diols, ${ }^{27}$ which we have recently utilized to selfassemble monometallic cryptates. ${ }^{28-31}$ We have also demonstrated that such cryptands exhibit adaptive behaviour upon addition of acid catalysts and metal ion templates. ${ }^{29} \mathrm{We}$ now report that the ammonium cation is sufficiently acidic to act both as a catalyst for orthoester exchange and as a template that governs the outcome of constitutional rearrangements (Scheme 1b). Experimental studies are accompanied by computational simulations designed to shed light on the transfer of $\mathrm{H}^{+}$from guest to host and to answer the question whether ammonium complexes of orthoester cryptands can be considered "fluxional host-guest complexes".

\section{RESULTS AND DISCUSSION}

Inherent adaptive behavior of orthoester cryptands. Following investigations on the adaptive behavior of orthoester cryptands in the presence of trifluoroacetic acid and alkali cations, ${ }^{29}$ we envisaged that the ammonium cation $\left(\mathrm{NH}_{4}{ }^{+}\right)$could also be a suitable template for the self-assembly of orthoester cryptates. Under typical conditions for self-assembly, ${ }^{28}$ we indeed observed ${ }^{1} \mathrm{H}$ NMR spectroscopic and ESI mass spectrometric evidence for ammonium cryptate formation. However, despite numerous attempts, we were not able to isolate the corresponding products, which we thought could be due the acidity of the $\mathrm{NH}_{4}^{+}$guest that would render the cryptate complexes constitutionally dynamic and exceptionally fragile to hydrolysis during work-up procedures. ${ }^{31}$ To verify this hypothesis, we tested $\mathrm{NH}_{4} \mathrm{BArF}$ (ammonium tetrakis[3,5bis(trifluoromethyl)phenyl]borate) ${ }^{32}$ as a catalyst for orthoester exchange between trimethyl orthoacetate and ethanol. The experiment revealed that the addition of $4 \mathrm{~mol} \%$ of $\mathrm{NH}_{4} \mathrm{BArF}$ was sufficient to reach equilibrium in this exchange reaction within only 10 minutes (Figure 1a and Figure S6).

Having established that $\mathrm{NH}_{4}{ }^{+}$indeed catalyzes orthoester exchange under conditions typically used for cryptate selfassembly, we monitored ammonium complexes of orthoester cryptands under careful exclusion of acid as well as light (possible formation of $\mathrm{HCl}$ from chloroform) and under the best-possible exclusion of water ${ }^{33}$ by means of ${ }^{1} \mathrm{H}$ NMR spectroscopy and $\mathrm{ESI}^{+}$mass spectrometry (Supporting Information). Symmetric cryptands $\boldsymbol{o}$-Me2-1.1.1 and $\boldsymbol{o}$-Me2-
2.2.2 based on either DEG (diethylene glycol) and TEG (triethylene glycol) building blocks were investigated first. Five hours after we added one equivalent of $\mathrm{NH}_{4} \mathrm{BArF}$ to cryptands $\boldsymbol{o}-\mathbf{M e}_{2}-\mathbf{1 . 1 . 1}$ or the larger cryptand $\boldsymbol{o}-\mathbf{M e}_{2}-\mathbf{2 . 2 . 2}$, which we had prepared by means of metal-templated self-assembly (Supporting Information), we observed clear evidence for orthoester exchange, i.e. formation of hydrolysis products (due to residual water) and higher orthoester oligomers (e.g., crown ethers) along with ca. $35 \%$ and $55 \%$ of the two respective starting materials.

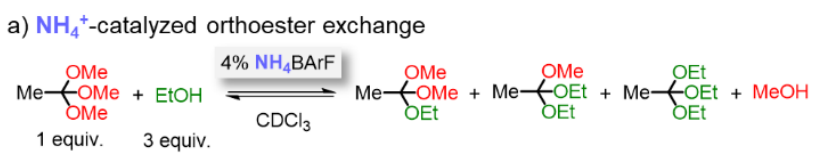

b) $\left[\mathrm{NH}_{4}{ }^{+} \subset \mathrm{O}-\mathrm{Me}_{2}-\mathbf{2 . 1 . 1}\right]$ : inherent adaptive behaviour

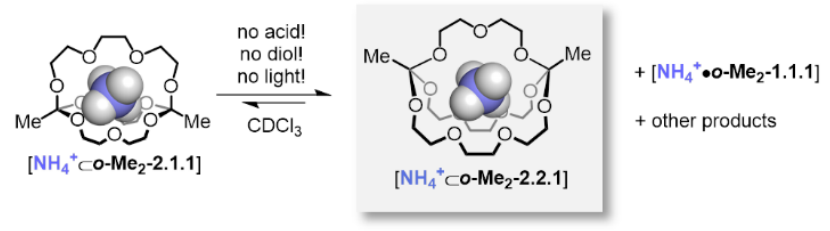

c) $\left[\mathrm{NH}_{4}{ }^{+} \mathrm{Co}-\mathrm{Me}_{2}-\mathbf{2 . 1 . 1}\right]:{ }^{1} \mathrm{H}$ NMR monitoring

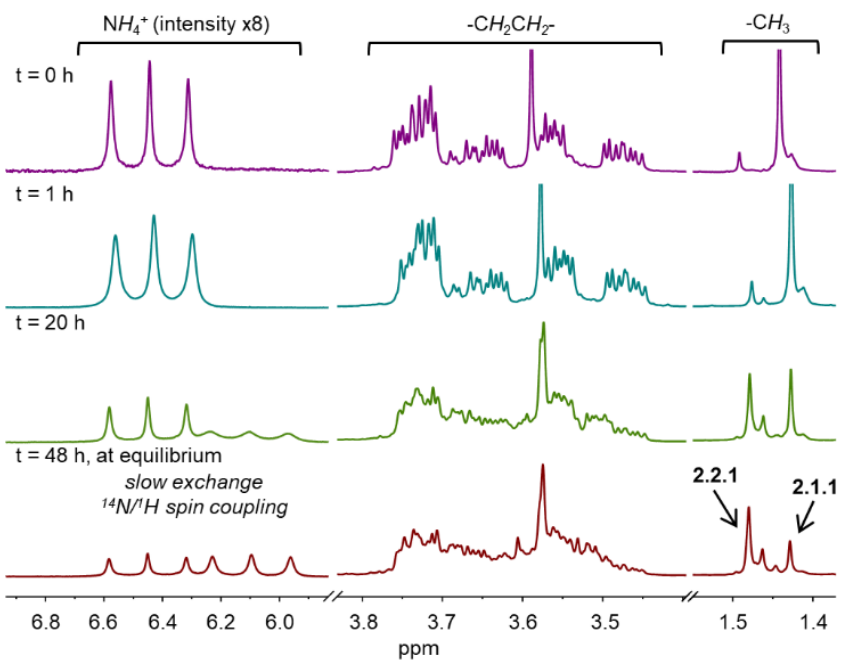

Figure 1. a) $\mathrm{NH}_{4} \mathrm{BArF}$-catalyzed orthoester exchange (orthoester concentration: $80 \mathrm{mM}$ ). b) Schematic representation of a key experiment on the inherent adaptive behavior of orthoester cryptate $\left[\mathrm{NH}_{4}{ }^{+} \subset \boldsymbol{o}-\mathrm{Me}_{2}-\mathbf{2 . 1 . 1}\right] \mathrm{BArF}^{-}$(cryptate concentration: $\left.80 \mathrm{mM}\right) . \mathrm{c}$ ) Partial ${ }^{1} \mathrm{H}$ NMR spectra of $\left[\mathbf{N H}_{4}{ }^{+} \subset \boldsymbol{o}-\mathbf{M e}_{2}-2.1 .1\right] \mathrm{BArF}^{-}$over time, showing the evolution from $\left[\mathbf{N H}_{4}{ }^{+} \subset \boldsymbol{o}-\mathbf{M e}_{2}-\mathbf{2 . 1 . 1}\right]$ to thermodynamically favored $\left[\mathbf{N H}_{4}{ }^{+} \subset \boldsymbol{o}-\mathbf{M e}_{2}-\mathbf{2 . 2 . 1}\right]$.

We next turned our attention to the more interesting unsymmetric cryptands $\boldsymbol{o}-\mathbf{M e}_{2}-\mathbf{2 . 1 . 1}$ and $\boldsymbol{o}-\mathbf{M e}_{2}-\mathbf{2 . 2 . 1}$, whose $\mathrm{NH}_{4}{ }^{+}$-catalyzed constitutional dynamics can give rise to the formation of all four possible cryptates (of type: 1.1.1, 2.1.1, 2.2.1 and 2.2.2) along with oligomers. As shown in Figure 1c, $\left[\mathbf{N H}_{4}{ }^{+} \subset \boldsymbol{o}\right.$-Me $\left.-\mathbf{M e}_{2}-\mathbf{1 . 1}\right]$ slowly converted over 48 hours to a mixture containing larger cryptate $\left[\mathbf{N H}_{4}{ }^{+} \subset \boldsymbol{o}-\mathbf{M e}_{2}-\mathbf{2 . 2 . 1}\right]$ as main product, suggesting that $\left[\mathbf{N H}_{4}{ }^{+} \subset \boldsymbol{o}-\mathbf{M e}_{2}-\mathbf{2 . 2 . 1}\right]$ is

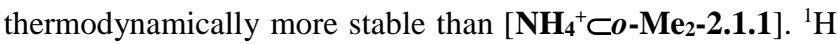
NMR integration shows that the ratio between these two compounds at equilibrium is ca. 2.5:1, which would indicate a free energy difference of ca. $0.5 \mathrm{kcal} \mathrm{mol}^{-1}$, if mass balance effects $^{30,31}$ were not taken into account. Even though the observation of some hydrolysis complicates the picture even 
further (Figure S13), it stands to reason that the mass balance in fact provides a bias towards smaller cryptate $\left[\mathrm{NH}_{4}{ }^{+} \subset \boldsymbol{o}-\mathbf{M e}_{2}-\right.$ 2.1.1] in this experiment, because simply speaking, there is not enough TEG available to form $\left[\mathbf{N H}_{4}{ }^{+} \subset \boldsymbol{o}-\mathbf{M e}_{2}-\mathbf{2 . 2 . 1}\right]$ exclusively, which forces the reaction in the opposite direction. As such, the thermodynamic preference for $\left[\mathbf{N H}_{4}{ }^{+} \subset \boldsymbol{o}-\mathbf{M e}_{2}-\right.$ 2.2.1] may well be larger than $0.5 \mathrm{kcal} \mathrm{mol}^{-1}$. Interestingly, the dynamic network seems to respond to the deficiency in TEG by forming the smallest cryptate $\left[\mathbf{N H}_{4}{ }^{+} \bullet \boldsymbol{o}-\mathbf{M e}_{2}-\mathbf{1 . 1 . 1}\right]$ as a major side product (ESI $\left.{ }^{+}-\mathrm{MS}\right)$.

If $\left[\mathbf{N H}_{4}{ }^{+} \subset \boldsymbol{o}-\mathbf{M e}_{2}-\mathbf{2 . 2 . 1}\right]$ is the thermodynamically most stable within the four possible cryptates, it is an intriguing question if and how this host-guest complex rearranges over time. A ${ }^{1} \mathrm{H}$ NMR monitoring study over 50 days showed that $\left[\mathbf{N H}_{4}{ }^{+} \subset \boldsymbol{o}-\right.$ Me2-2.2.1] remains the dominant library member over the entire period (Figure S18). It should be noted that we can be rather certain that the library is in fact dynamic, because we observe a slow increase of hydrolysis products DEG (diethylene glycol), TEG (triethylene glycol) and esters that require the formation of the same oxonium intermediates that are involved in orthoester exchange. The observation of esters can thus be considered as "trapping" of oxonium ions (Supporting Information, Scheme S1 and Figure S19 for further trapping experiments). A noteworthy NMR spectroscopic phenomenon in the unsymmetric cryptates is that heteronuclear spin-spin coupling between ${ }^{1} \mathrm{H}$ and ${ }^{14} \mathrm{~N}$ in $\mathrm{NH}_{4}{ }^{+}$was observed. We suggest that this phenomenon is due to slow exchange kinetics of the acidic $\mathrm{NH}_{4}{ }^{+}$protons, which only seems to be the case in the two more strongly binding cryptates $\left[\mathrm{NH}_{4}{ }^{+} \subset \boldsymbol{o}-\mathbf{M e}_{2}-\mathbf{2 . 1 . 1}\right]$ and $\left[\mathrm{NH}_{4}{ }^{+} \subset \boldsymbol{o}-\mathbf{M e}_{2}-2.2 .1\right]$ (Figure 2b).

The extent of hydrolysis in the rearrangement of $\left[\mathrm{NH}_{4}^{+} \subset \boldsymbol{o}\right.$ $\left.\mathbf{M e}_{2}-\mathbf{2 . 1 . 1}\right]$ to $\left[\mathrm{NH}_{4}{ }^{+} \subset \boldsymbol{o}-\mathrm{Me}_{2}-\mathbf{2 . 2 . 1}\right]$ gave us a valuable clue regarding the mechanism of such cage-to-cage transformations, because we noticed that the rearrangement proceeds significantly faster in experiments where more than the typically observed $10-20 \%$ of hydrolysis had occurred due to inadequately dried reagents. ${ }^{33}$ The mechanistic implication of this finding is that free diols generated by hydrolysis are most likely the species that do attack oxonium ions and thus lead to the rearrangement of one cryptate into another. ${ }^{26,35}$ An alternative, less likely mechanistic scenario would involve diol scrambling via compounds, in which a diol forms a bridge between two cages (Scheme S2).

To provide further support for our hypothesis that $\left[\mathrm{NH}_{4}{ }^{+} \subset \boldsymbol{o}-\right.$ Me2-2.2.1] is the thermodynamically most stable complex within the series of ammonium cryptates, we carried out experiments, in which TEG or DEG was added to freshly prepared cryptates $\left[\mathrm{NH}_{4}{ }^{+} \bullet \boldsymbol{o}-\mathrm{Me}_{2}-\mathbf{1 . 1 . 1}\right],\left[\mathrm{NH}_{4}{ }^{+} \subset \boldsymbol{o}-\mathbf{M e}_{2}-\mathbf{2 . 1 . 1}\right]$, and $\left[\mathbf{N H}_{4}{ }^{+} \subset \boldsymbol{o}-\mathbf{M e}_{2}-\mathbf{2 . 2 . 2}\right]$ (Figure 2). In all three experiments, relatively fast orthoester exchange kinetics were observed, e.g. equilibration in $4 \mathrm{~h}$ instead of $48 \mathrm{~h}$, further supporting our mechanistic hypothesis. More importantly, $\left[\mathbf{N H}_{4}{ }^{+} \subset \boldsymbol{o}-\mathbf{M e}_{2}-\right.$ 2.2.1] was found to be the major product at equilibrium in these experiments (Figure 2b), which we conducted in such a way that there is no mass balance bias between pairs of cryptates (e.g. between $\boldsymbol{o}-\mathbf{M e}_{2}-2.1 .1$ and $\boldsymbol{o}-\mathbf{M e}_{2}-2.2 .1$ in Figure 2a, top). It is also worth noting that particularly low extents of hydrolysis were observed in these fast reactions, e.g. only $6 \%$, suggesting that higher extents of hydrolysis in experiments that required significantly longer equilibration times were likely due to water influx. a)
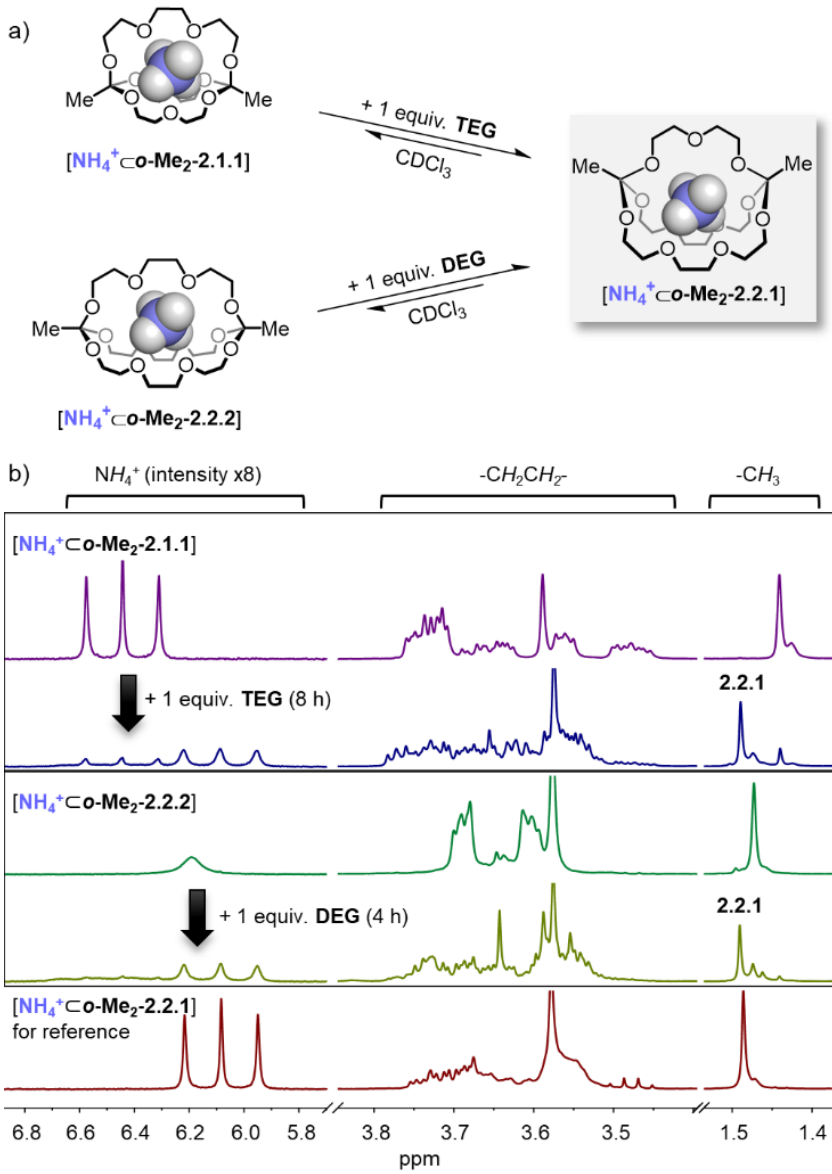

Figure 2. a) Schematic representation and b) partial ${ }^{1} \mathrm{H}$ NMR spectra corresponding to the adaptive behavior of $\left[\mathrm{NH}_{4}{ }^{+} \subset \boldsymbol{o}-\mathrm{Me}_{2}-\right.$ 2.1.1] and $\left[\mathrm{NH}_{4}{ }^{+} \subset \boldsymbol{o}-\mathrm{Me}_{2}-2.2 .2\right]$ in the presence of 1 equivalent of TEG or DEG, respectively (Cryptate concentrations: $80 \mathrm{mM}$ ).

Thermodynamics of ammonium binding and solid state structure of $\left[\mathrm{NH}_{4}{ }^{+} \subset \boldsymbol{o}-\mathrm{Me}_{2}-2.2 .1\right] \mathrm{BArF}^{-}$. In order to better understand the thermodynamic origins of the observed adaptive behaviour that is inherent to these host-guest systems, we determined the binding constants between all four cryptands and $\mathrm{NH}_{4}{ }^{+}$in anhydrous $\mathrm{MeCN}-\mathrm{d}_{3}$ by ${ }^{1} \mathrm{H}$ NMR spectroscopy (Figure 3 and Table 1). To minimize hydrolysis and competing intermolecular dynamic exchange processes, NMR spectra were recorded as fast as possible in J-Young tubes and the experiments were carried out at lower concentrations compared to the experiments on adaptive behaviour. As shown in Figure 3b, after adding $\mathrm{NH}_{4} \mathrm{BArF}$ to cryptand $\boldsymbol{o}$-Me-2.2.1 in $\mathrm{MeCN}$ $\mathrm{d}_{3}$, the ${ }^{1} \mathrm{H}$ NMR signal of the methyl bridgehead shifted to low field, indicating the formation of cryptate $\left[\mathrm{NH}_{4}{ }^{+} \subset \boldsymbol{o}-\mathbf{M e}_{2}-\mathbf{2 . 2 . 1}\right.$, as well as fast exchange kinetics in this solvent. Interestingly, with more than one equivalent of $\mathrm{NH}_{4} \mathrm{BArF}$, the triplet of the $\mathrm{NH}_{4}{ }^{+}$protons converge to a broad peak, further confirming that the observation of ${ }^{1} \mathrm{H} /{ }^{14} \mathrm{~N}$ spin-spin coupling is somewhat correlated with guest inclusion. Data fitting using supramolecular.org according to $1: 1$ stoichiometry gave a binding constant $\left(K_{a}\right)$ of ca. $6,000 \mathrm{M}^{-1}$ for this host-guest complex. 

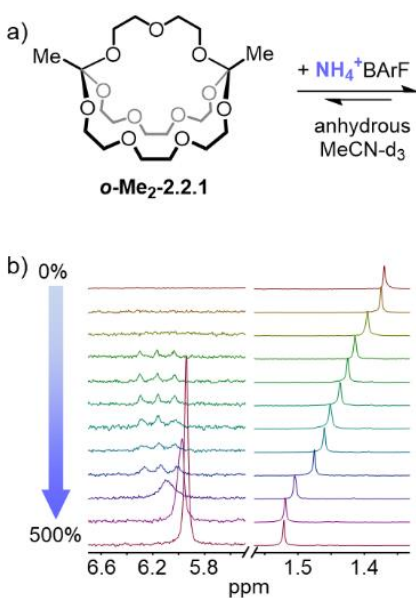

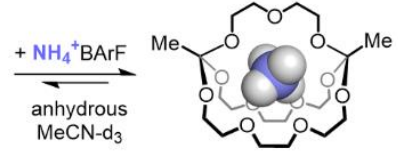

$\left[\mathrm{NH}_{4}{ }^{+} \subset \mathrm{Co}-\mathrm{Me}_{2}-\mathbf{2 . 2 . 1}\right]$

immediate ${ }^{1} \mathrm{H}$ NMR analysis

c)

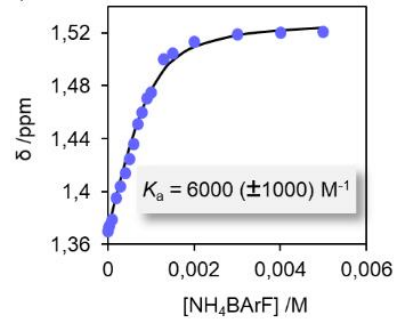

Figure 3. a) Schematic representation of titration of $\boldsymbol{o}-\mathbf{M e}_{2}-$ 2.2.1 with $\mathrm{NH}_{4} \mathrm{BArF}$. b) Partial ${ }^{1} \mathrm{H}$ NMR (400 MHz, $298 \mathrm{~K}$, $\left.\mathrm{CD}_{3} \mathrm{CN}\right)$ stack plot for titration of $\boldsymbol{o}-\mathbf{M e}_{2}-\mathbf{2 . 2 . 1}(1.0 \mathrm{mM})$ with $\mathrm{NH}_{4}$ BArF. c) Binding isotherm for titration of $\boldsymbol{o}-\mathbf{M e}_{2}-\mathbf{2 . 2 . 1}$ with $\mathrm{NH}_{4} \mathrm{BArF}$. Blue spheres: experimental points, black line: fit according to 1: 1 model.

The binding constants of $\boldsymbol{o}-\mathbf{M e}_{2}-\mathbf{1 . 1 . 1}, \boldsymbol{o}-\mathbf{M e}_{2}-\mathbf{2 . 1 . 1}$, and $\boldsymbol{o}$ Me2-2.2.2 with $\mathrm{NH}_{4} \mathrm{BArF}$ were determined in the same manner (Supporting Information) and the results are summarized in Table 1. Even though experiments on adaptive behaviour were carried out in less polar solvent chloroform, these results in acetonitrile corroborate that $\boldsymbol{o}-\mathbf{M e}_{2}-\mathbf{2 . 2} .1$ possesses the highest affinity towards $\mathrm{NH}_{4}{ }^{+}$. We also investigated the complexation of methylammonium, which binds significantly weaker to all four cryptands, while unsymmetric cryptands $\boldsymbol{o}$-Me2-2.2.1, and $\boldsymbol{o}-\mathbf{M e}_{2}-2.1 .1$ are also the preferred hosts for this larger cation. Finally, we tested whether the larger, $\mathrm{D}_{3} \mathrm{~h}$-symmetric and less acidic guanidinium ion would potentially be an ideal guest for the $\boldsymbol{o}$-Me $\mathbf{M}_{2}-\mathbf{2 . 2 . 2}$ cryptand. Based on the observed binding constant of ca. $70 \mathrm{M}^{-1}$, we suggest that this complex does either not fit the cavity of this cryptand or that there is simply no strain-free conformation available that would allow effective hydrogen bonding between host oxygen atoms and the six guanidinium hydrogen atoms.

Table 1. Binding constants $\left(K_{\mathrm{a}}\right)$ for three representative nitrogen-based cations ${ }^{\mathrm{a}}$

\begin{tabular}{llll}
\hline$K_{\mathrm{a}}\left(\mathrm{M}^{-1}\right)$ & $\mathrm{NH}_{4}{ }^{+}$ & $\mathrm{CH}_{3} \mathrm{NH}_{3}{ }^{+}$ & $\mathrm{C}\left(\mathrm{NH}_{2}\right)_{3}{ }^{+}$ \\
\hline $\boldsymbol{o}-\mathrm{Me}_{2}-1.1 .1$ & $540 \pm 40$ & $290 \pm 10$ & n.d. \\
$\boldsymbol{o}-\mathrm{Me}_{2}-2.1 .1$ & $1100 \pm 100$ & $750 \pm 30$ & n.d. \\
$\boldsymbol{o}-\mathrm{Me}_{2}-2.2 .1$ & $\mathbf{6 0 0 0} \pm \mathbf{1 0 0 0}$ & $1700 \pm 20$ & n.d. \\
$\boldsymbol{o}-\mathrm{Me}_{2}-\mathbf{2 . 2 . 2}$ & $400 \pm 30$ & $120 \pm 10$ & $70 \pm 10$ \\
\hline
\end{tabular}

${ }^{a}{ }^{1} \mathrm{H}$ NMR titrations carried out in separate J-Young tubes (solvent: $\quad \mathrm{MeCN}_{-} \mathrm{d}_{3}$; counteranions: tetrakis[3,5bis(trifluoromethyl)phenyl]borate). In the spirit of open-science, ${ }^{37}$ the raw data is available on supramolecular.org (see Supporting Information for hyperlinks). Errors reflect goodness of fit.

The high thermodynamic stability of cryptand $\left[\mathrm{NH}_{4}^{+} \subset \boldsymbol{o}\right.$ $\mathrm{Me}_{2}$-2.2.1]BArF and thus relatively low propensity of this compound to undergo intermolecular rearrangements allowed us to obtain crystallographic data on this host-guest architecture. Suitable single crystals were obtained by slow vapor diffusion of anhydrous n-pentane into a solution of $\left[\mathrm{NH}_{4}{ }^{+} \subset \boldsymbol{o}-\mathrm{Me}_{2}-2.2 .1\right] \mathrm{BArF}{ }^{-}$in $\mathrm{CDCl}_{3}$ in a well-sealed vial devoid of moisture. As shown in Figure 4, the solid state structure unambiguously confirms the inclusion of $\mathrm{NH}_{4}{ }^{+}$into the cavity of cryptand $\boldsymbol{o}-\mathbf{M e}_{2}-\mathbf{2 . 2 . 1}$. The nitrogen atom is located at the centre of the cavity, as becomes evident from $\mathrm{N}-\mathrm{O}$ distances in the relatively narrow range of $2.69-3.55 \AA$. The cryptand framework is somewhat less symmetric compared to previously reported crystal structures of alkali metal complexes of orthoester cryptands, ${ }^{28,29,31}$ which is also observed in simulations (vide infra), but could in principle also be due to packing effects. X-Ray crystallography does unfortunately not provide information on the location of the ammonium hydrogen atoms, which is one of the reasons why we decided to investigate the structural and dynamic behavior of the cryptates in more detail by computational methods.

a)

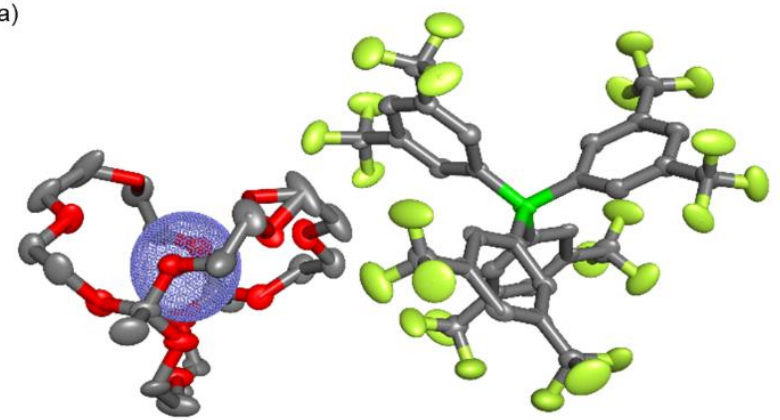

b)
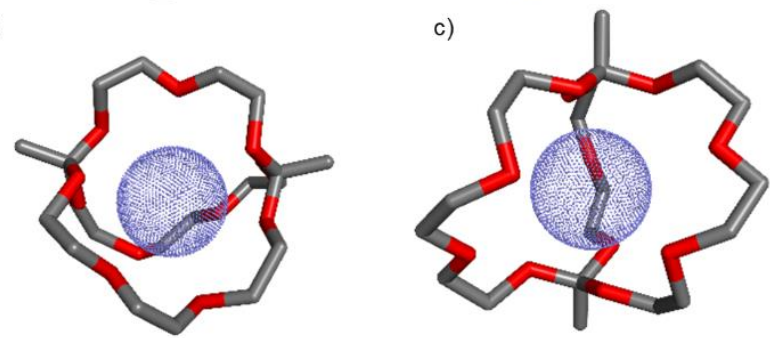

Figure 4. a) Solid state structure of $\left[\mathrm{NH}_{4}{ }^{+} \subset \boldsymbol{o}-\mathrm{Me}_{2}-2.2 .1\right] \mathrm{BArF}^{-}$. b) Side view and c) top view of cryptate complex $\left[\mathbf{N H}_{4}{ }^{+} \subset \boldsymbol{o}-\mathbf{M e}_{2}-\right.$ 2.2.1]. Hydrogen atoms, solvent and disorder (where applicable) are omitted for clarity. Carbon: grey, nitrogen: purple, oxygen: red, fluorine: yellow, boron: green.

Computational studies of ammonium binding. The intrinsic flexibility and reactivity of the described ammonium orthoester cryptates results in a complex dynamic picture of their behaviour. Hence, we chose classical molecular-dynamics (MD), hybrid quantum mechanics molecular mechanics (QM/MM) simulations, and static DFT calculations to investigate the structure.

From classical atomistic MD simulations of the cryptates in chloroform (detailed methods described in section 5.1 of the Supporting Information) we were able to retrieve a dynamic picture of the cryptates' structural flexibility and their hydrogen bonding with $\mathrm{NH}_{4}{ }^{+}$. Not surprisingly the flexibility of the systems increases with increasing size of the cryptand framework from $\boldsymbol{o}-\mathrm{Me}_{2}-1.1 .1$ over $\boldsymbol{o}-\mathrm{Me}_{2}-2.1 .1$ to $\boldsymbol{o}-\mathrm{Me}_{2}-2.2 .2$, as demonstrated by higher atomic root mean square fluctuation (rmsf) values extracted from $200 \mathrm{~ns}$ simulations (Figure 5a-b and Table S11). The differences in flexibility seem to be driven by how well the ion fits into and forms favourable interactions within the cavity. When compared with flexibility patterns of monometallic cryptates (Figure S43 and Table S11, Supporting Information), the ammonium cryptates resemble most closely the $\mathrm{Rb}^{+}$cryptates, which also preferentially self-assembles into the $\left[\mathbf{R b}^{+} \subset \boldsymbol{o}-\mathbf{M e}_{2}-\mathbf{2 . 2 . 1}\right]$ cage. $^{29}$ 


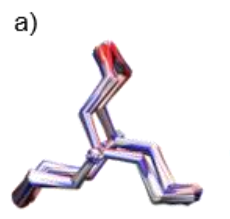

b)

$\left[\mathrm{NH}_{4}{ }^{+} \subset \mathrm{Co}-\mathrm{Me}_{2}-1.1 .1\right]$
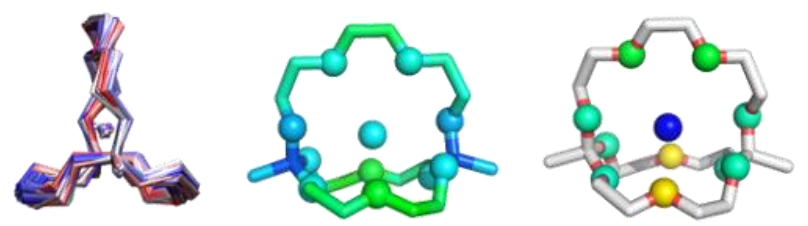

$\left[\mathrm{NH}_{4}{ }^{+} \subset 0-\mathrm{Me}_{2}-2.1 .1\right]$

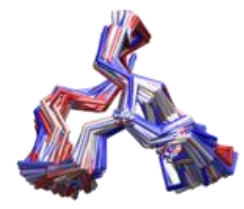

$\left[\mathrm{NH}_{4}{ }^{+} \subset \mathrm{CO}-\mathrm{Me}_{2}-2.2 .1\right]$
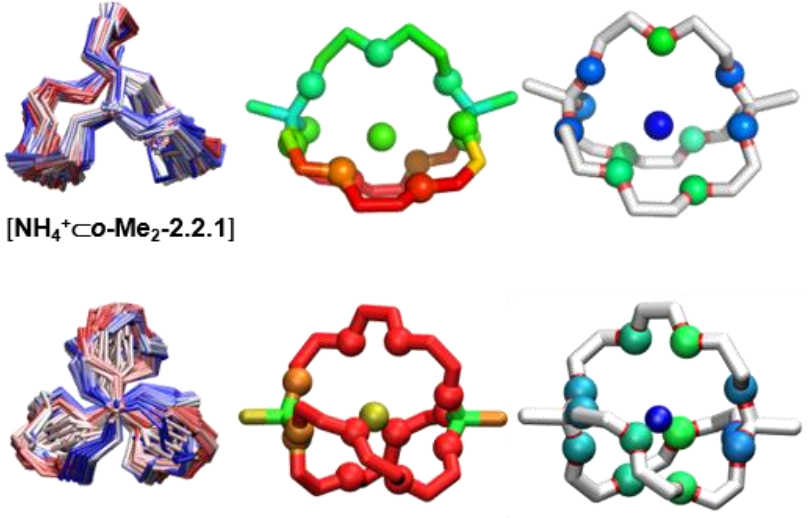

$\left[\mathrm{NH}_{4}{ }^{+} \mathrm{CO}-\mathrm{Me}_{2}-2.2 .2\right]$
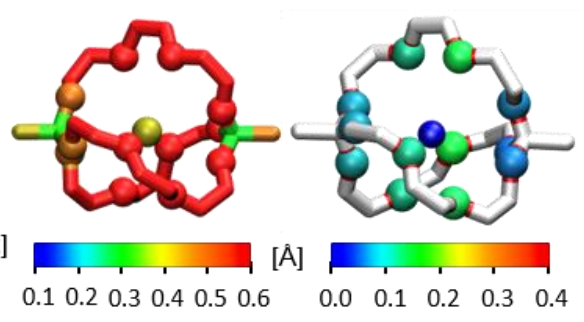

Figure 5. a) Flexibility of cryptands illustrated by superimposed and smoothed snapshots from 200 ns MD simulations color coded by simulation time, b) RMSF fluctuations (in $\AA$ ) and c) hydrogen bonding occupancy derived from $200 \mathrm{~ns}$ MD simulations mapped on averaged cryptate structures. Oxygen and nitrogen atoms shown as spheres, hydrogen atoms omitted for clarity.

The trends in flexibility are also reflected in the hydrogen bonding features of the encapsulated ammonium ions (Figure 5b, Table S12) with average hydrogen bonding numbers of $1.3,1.1,1.7$, and 3.3 following decreasing cryptand size. More importantly, hydrogen bonds between $\mathrm{NH}_{4}{ }^{+}$and ether oxygens $\left(\mathrm{O}_{\mathrm{e}}\right)$ are preferred over orthoester oxygens $\left(\mathrm{O}_{\mathrm{o}}\right)$, and hydrogen bonds to DEG oxygens are preferred over TEG oxygens. The average occupancy of hydrogen bonds to $\mathrm{O}_{\mathrm{o}}$ drops from 0.25 for $\left[\mathbf{N H}_{4}^{+} \bullet-\mathbf{M e}-\mathbf{M}-1.1\right]$ to the minimum of 0.04 for $\left[\mathbf{N H}_{4}{ }^{+} \subset \boldsymbol{o}-\mathbf{M e}_{2}-\mathbf{2 . 2 . 1}\right]$ with the latter additionally having the highest $\mathrm{O}_{\mathrm{e}}: \mathrm{O}_{\mathrm{o}}$ hydrogen bond ratio (3.6:1) in the series. In other words, hydrogen bonding to orthoester oxygens is very limited in this cryptate, which might influence its thermodynamic and kinetic stability (tendency to form an oxonium ion intermediate).
Additionally, it becomes apparent from these simulations that $\boldsymbol{o}-\mathrm{Me}_{2}-\mathbf{1 . 1 . 1}$ is essentially too small to accommodate the $\mathrm{NH}_{4}{ }^{+}$ ion, resulting in an exo mode of binding, whereas $\boldsymbol{o}-\mathbf{M e}_{2}-\mathbf{2 . 2 . 2}$ is too large and leads to a highly dynamic endo mode of binding. a)

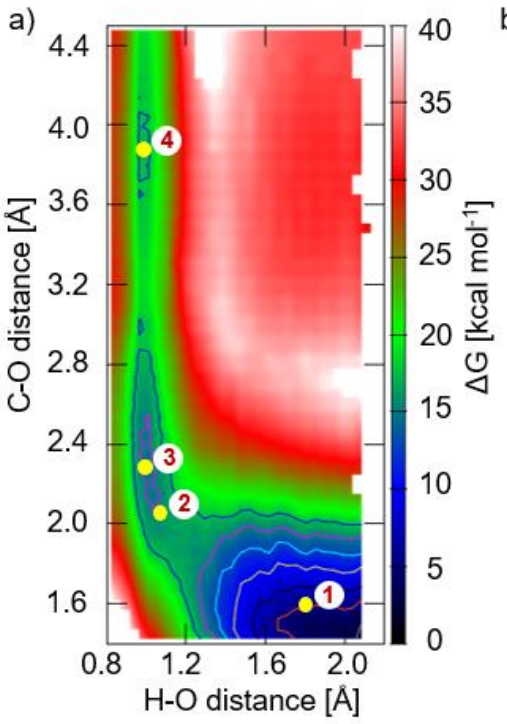

b)

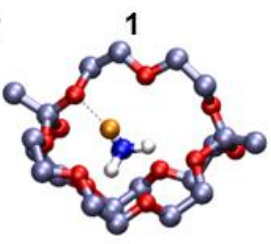

2

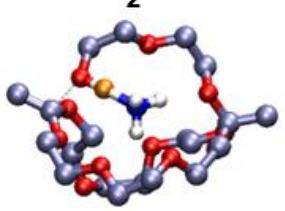

3

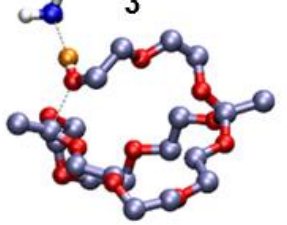

Figure 6. a) Free energy representation of a two-dimensional QM/MM umbrella sampling trajectory of oxonium ion formation of $\left[\mathrm{NH}_{4}{ }^{+} \subset \mathbf{0}-\mathrm{Me}_{2}-\mathbf{2 . 2 . 1}\right]$. Bond forming between the orthoester oxygen and the hydrogen from $\mathrm{NH}_{4}{ }^{+}$ion and the carbon oxygen bond breakage have been used as sampling coordinates. Energies given in $\mathrm{kcal} \mathrm{mol}^{-1}$, contour lines shown represent steps of $2.5 \mathrm{kcal} \mathrm{mol}^{-1}$ between 2.5 and $20.0 \mathrm{kcal} \mathrm{mol}^{-1}$. b) Representative structures at characteristic points from this simulation. All cryptand hydrogens omitted for clarity. Hydrogen involved in reaction shown in orange.

More detailed umbrella sampling simulations to pull the ammonium ion out of the cavity into the solvent (Supporting Information, section 5.3 and Figure S46) support these observations, in which a distinct barrier between exo and endo binding is observable for $\left[\mathbf{N H}_{4}^{+} \bullet-\mathbf{M e}-\mathbf{- 1 . 1 . 1}\right.$. Regarding the two unsymmetric cryptates, the simulations suggest that within the series of cryptands the exo association is most favourable for $\left[\mathbf{N H}_{4}{ }^{+} \subset \boldsymbol{o}-\mathbf{M e}_{2}-\mathbf{2 . 2 . 1}\right]$ by $3.8 \mathrm{kcal} \mathrm{mol}{ }^{-1}$ over $\left[\mathbf{N H}_{4}{ }^{+} \boldsymbol{\bullet} \boldsymbol{o}-\mathbf{M e}_{2}-\right.$ 1.1.1] and $4.5 \mathrm{kcal} \mathrm{mol}^{-1}$ over $\left[\mathbf{N H}_{4}{ }^{+} \subset \boldsymbol{o}-\mathbf{M e}_{2}-\mathbf{2 . 1 . 1}\right.$ ], while endo binding is significantly more stable than exo binding in both unsymmetric cryptands (e.g. $\left[\mathbf{N H}_{4}{ }^{+} \subset \boldsymbol{o}-\mathbf{M e}_{2}-\mathbf{2 . 1 . 1}\right]$ favored by $2.5 \mathrm{kcal} \mathrm{mol}^{-1}$ ). Thus, the simulations are in good qualitative agreement with the experimental association constants (Table 1), while the subtle difference in affinity between $\boldsymbol{o}$-Me $\mathbf{M}_{2}-\mathbf{2 . 1 . 1}$ and $\boldsymbol{o}-\mathbf{M e}_{2}-2.2 .1$ is beyond the limitations of this computational method. Additional Density Functional Theory (DFT) calculations starting 
a)
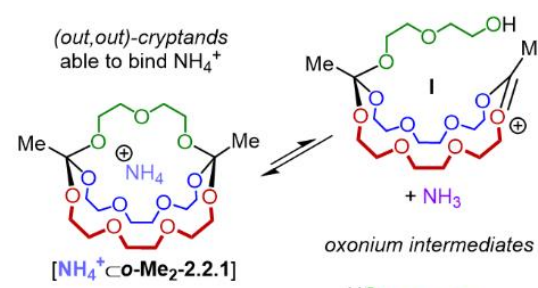

oxonium intermediates
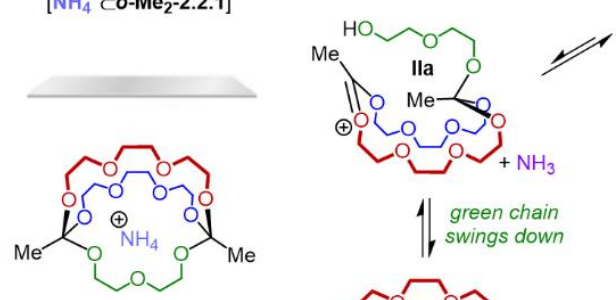

III

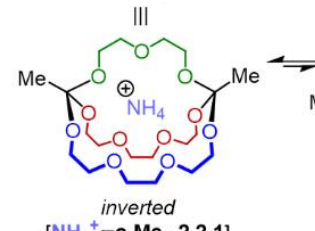

$\left[\mathrm{NH}_{4}{ }^{+} \mathrm{CO}-\mathrm{Me}_{2}-2.2 .1\right]$ b)
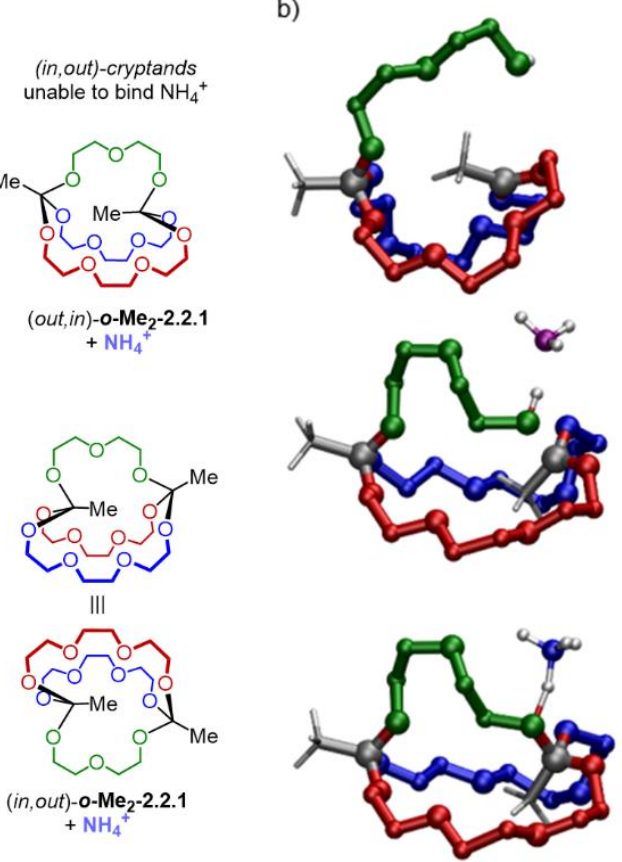

unable to bind $\mathrm{NH}_{4}{ }^{+}$

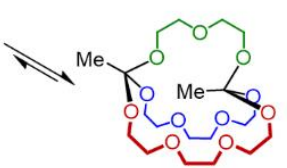

(out, in)-o-Me -2.2 .1$ $+\mathrm{NH}_{4}{ }^{+}$

$+\mathrm{NH}_{4}^{+}$ c)
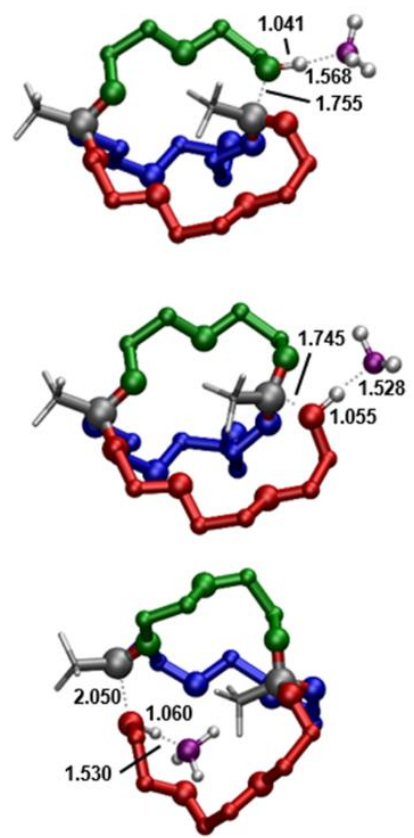

Figure 7. a) Reaction sequence of a "fluxional" intramolecular rearrangement leading to exchange of the two triethylene glycol chains via several ring-opening and -closing reactions. b) Snapshots extracted from QM/MM umbrella sampling simulations for the backside attack of the oxonium ion to form the inverted $\boldsymbol{o}-\mathbf{M e}_{2}-2.2 .1$ (out,in) intermediate. All $\mathrm{CH}_{2}$ hydrogens omitted for clarity. Orthoester atoms of different side chains highlighted in different colours in analogy to part a of this Figure. c) DFT optimized transition state structures for the ringopening of the $\boldsymbol{o}$-Me2-2.2.1 (out,in) intermediate. Selected interatomic distances given in $\AA$.

from selected snapshots of these simulations (Supporting Information, section 5.8) and carried out with implicit solvation additionally indicate that $\left[\mathbf{N H}_{4}{ }^{+} \subset \boldsymbol{o}-\mathbf{M e}_{2}-\mathbf{2 . 2 . 1}\right]$ is thermodynamically the most stable cryptate. Calculating the reaction energies (zero point corrected free energies) of the cryptate formation also shows that the Gibbs free energies in chloroform is always exergonic with the formation of $\left[\mathrm{NH}_{4}{ }^{+} \subset \boldsymbol{o}-\mathrm{Me}_{2}-\mathbf{2 . 2 . 1}\right]$ being the most favourable.

Computational studies of proton transfer and cage opening. The formation of oxonium ions as key intermediates for orthoester exchange reactions, as shown in Scheme 1, was investigated by means of combined quantum mechanical and molecular mechanics (QM/MM) simulations. Here, the cryptand and the ammonium ion were treated by the density functional based tight binding method (DFTB), ${ }^{38}$ while the solvent was treated by classical molecular mechanics (Supporting Information, section 5.4-5.6). Based on these simulations, the cryptand-opening was first simulated using umbrella sampling. To investigate if the mechanism is stepwise or concerted we carried out two-dimensional umbrella sampling scans investigating the energy profile for the $\mathrm{C}-\mathrm{O}_{\mathrm{o}}$ bond breakage and the $\mathrm{H}-\mathrm{O}_{0}$ simultaneously (Figure 6). The ring opening transition state indeed represents a concerted mechanism with simultaneous proton transfer and $\mathrm{C}-\mathrm{O}$ bond dissociation. The barrier of $16.2 \mathrm{kcal} \mathrm{mol}^{-1}$ and the strongly endergonic character remain comparable with the 1D scan for $\left[\mathrm{NH}_{4}{ }^{+} \subset \boldsymbol{o}-\mathrm{Me}_{2}-\mathbf{2 . 2 . 1}\right]$. Therefore, these results confirm that the formation of the oxonium ion is very slow due to a high barrier and that the concentration of free oxonium ions must be very small. Another observation was that in all simulations, the formed $\mathrm{NH}_{3}$ tends to leave the open cryptand cage after oxonium ion formation, which is in agreement with the results of trapping experiments (Figure S19).

In summary, our simulations show that oxonium ion formation by proton transfer from an encapsulated ammonium ion is plausible, but subject to a significant kinetic barrier, which is very similar for $\left[\mathbf{N H}_{4}{ }^{+} \subset \boldsymbol{o}-\mathbf{M e}_{2}-\mathbf{2 . 2 . 1}\right]$ and $\left[\mathbf{N H}_{4}{ }^{+} \subset \boldsymbol{o}-\right.$ Me2-2.1.1]. One of the reasons for the high barrier for ringopening seems to lie in the fact that the strong hydrogen bonding network of the ammonium ion decreases its reactivity (acidity) significantly, which is a well-established effect often referred to as "complexation-induced $\mathrm{p} K_{\mathrm{a}}$ shift". ${ }^{39-41} \mathrm{DFT}$ calculations based on the QM/MM simulations (Supporting Information, section 5.9) show that the protonation and ring opening barriers are predominately influenced by the number of hydrogen bonds formed with the cage.

Based on these considerations, ammonium ions approaching from the outside of the cage should demonstrate higher acidity and reactivity. However, this attack competes with the high driving force to enter the cavity and all QM/MM umbrella sampling approaches for this reaction step with $\boldsymbol{o}$-Me2-2.2.1 resulted in the highly stable encapsulated configuration and no ring-opening attack. Moreover, the free energy difference associated with $\mathrm{NH}_{4}{ }^{+}$dissociation is more endergonic than the kinetic barrier for ring opening (in case of $\mathrm{NH}_{4}{ }^{+} \subset \boldsymbol{o}-\mathbf{M e}_{2}-2.2 .1$ and $\left.\mathbf{N H}_{4}{ }^{+} \subset \boldsymbol{o}-\mathbf{M e}_{2}-\mathbf{2 . 1 . 1}\right)$. We therefore consider it highly unlikely that adaptive behavior would be based on the dissociation of the ammonium ion.

Are these host-guest complexes fluxional? Finally, we attempted to answer the question whether the ammonium cryptates are undergoing intramolecular rearrangements in a 
manner that would meet the definition of fluxionality according to IUPAC. ${ }^{1}$

As shown in Figure 7a, the first step for such a rearrangement would be oxonium ion formation (vide supra), leading to release of $\mathrm{NH}_{3}$ into the solvent. Oxonium ion I is essentially a lariate crown ether ${ }^{42-44}$ whose alcohol group can attack the electrophilic carbon atom from the opposite side from where it left and therefore invert the absolute configuration at this bridgehead (Figure 7a-b). The possible formation of this (out,in) intermediate structure was confirmed for $\boldsymbol{o}$-Me2-2.2.1 by umbrella sampling simulations. Unsurprisingly, the (out,in) cage is not able to accommodate an ammonium ion within its cavity (Supporting Information, section 5.7-5.8). Thus, the reactivity of this species will not be decreased by strong hydrogen bonding networks and attack by external ammonium ions should be fast, which is confirmed by DFT calculations presented in section 5.9 of the Supporting Information. Also, the fact that (out,in) cryptands cannot accommodate the $\mathrm{NH}_{4}{ }^{+}$ ion helps to explain why such species are not observed in significant quantities during our experiments (thermodynamic control provides a strong driving force for effective hosts).

DFT transition state calculations (Figure 7c and section 5.9 of the Supporting Information) at the PBE0/def2TZVP(D3) level of theory provided barriers for ring-opening by proton transfer between 1.3 and $26.3 \mathrm{kcal} \mathrm{mol}^{-1}$ for either side of the $\boldsymbol{o}$ Me2-2.2.1 (out,in) intermediate. As indicated in the previous section, the large difference between the activation barriers is related to the nature of non-covalent interactions of $\mathrm{NH}_{4}{ }^{+}$with the host in the optimized precursor structures. For cases where $\mathrm{NH}_{4}{ }^{+}$is engaged in strong hydrogen bonding, the barrier is high, whereas the barrier is minimal, if the cation is only associated to one orthoester oxygen atom. In general, the reactivity of $\mathrm{NH}_{4}{ }^{+}$decreases with effective encapsulation, and $\mathrm{NH}_{4}{ }^{+}$should be most reactive in conjunction with hosts $\boldsymbol{o}-\mathbf{M e}_{2}-\mathbf{1 . 1 . 1}$ and (out,in)-o-Me2-2.2.1 and least reactive for $\boldsymbol{o}-\mathbf{M e}_{2}-2.2 .1$ and $\boldsymbol{o}$ Me-2.1.1.

To complete the fluxional rearrangement sequence, the second orthoester oxygen of the diethylene glycol chain (green in Figure 7) needs to be involved in a second ring opening step, so that the cryptand can subsequently undergo inversion of the second bridgehead (via backside attack) to form an inverted (out,out) configuration with encapsulated ammonium ion (Figure 6a). From the structures displayed on the left hand side of Figure 7, it is evident that the two triethylene glycol chains (red and blue) have now changed position and that their stereochemical relationship is enantiotopic (mirror plane in Figure 7).

The described inversion pathway based on the formation of an (in,out) cryptand and reactive oxonium ions $\mathbf{I}$ and $\mathbf{I I}$ is plausible for three reasons. Firstly, the formed $\mathrm{NH}_{3}$ dissociates after ring opening, which allows the flexible side chains to adopt conformations suitable for back side attack and ring closure as a key process leading to stereochemical inversion. Secondly, the (out,in) cryptand as a key intermediate has a calculated ground state energy that is $7.2 \mathrm{kcal} \mathrm{mol}^{-1}$ more stable than the corresponding empty o-Me2-2.1.1 cryptand (5.2 $\mathrm{kcal} \mathrm{mol}^{-1}$ in case of $\boldsymbol{o}$-Me2-2.2.1), which suggests that its formation is possible, even though it cannot encapsulate the $\mathrm{NH}_{4}{ }^{+}$ion. Thirdly, for that same reason, the formed reactive (out,in) cryptand is equally prone to $\mathrm{NH}_{4}{ }^{+}$attack on both sides of the molecule (if no additional hydrogen bonds are formed) leading to a stochastic chance for ring opening on both sides including the described pathway. We therefore conclude that there is a plausible pathway for "fluxional" intramolecular degenerate rearrangements in the $\left[\mathbf{N H}_{4}{ }^{+} \subset \boldsymbol{o}-\mathbf{M e}_{2}-\mathbf{2 . 2 . 1}\right]$ hostguest complex with each elementary step of the corresponding reaction sequence supported by computational evidence (DFT, QM/MM, and MD simulations).

\section{CONCLUSION}

In this study, we demonstrated experimentally that the ammonium complexes of orthoester cryptands are highly unusual chemical species. The ammonium guest is sufficiently acidic to initiate orthoester exchange and thus imparts constitutional dynamics onto the covalent framework of the host. The inherently dynamic nature of these host-guest complexes became evident in experiments, in which the unsymmetric cryptate $\left[\mathbf{N H}_{4}{ }^{+} \subset \boldsymbol{o}-\mathbf{M e}_{2}-\mathbf{2 . 1 . 1}\right]$ spontaneously rearranged into the thermodynamically more stable cryptate $\left[\mathbf{N H}_{4}{ }^{+} \subset \boldsymbol{o}-\mathbf{M e}_{2}-\mathbf{2 . 2 . 1}\right]$ by means of intermolecular subcomponent exchange. In the context of decades of work on supramolecular hosts acting as "artificial enzymes", ${ }^{45-50}$ this study therefore represents a rare complement, because in this case the modulation of reactivity occurs from the guest to the host, ${ }^{51-54}$ and not in the other direction.

Comprehensive computational studies confirmed that the crucial step for constitutional cryptate rearrangement, i.e. the formation of oxonium ion intermediates is significantly hindered by the ammonium ion's ability to strongly bind to the cryptands through multiple hydrogen bonds and the associated complexation-induced $\mathrm{pK}_{\mathrm{a}}$ shift. This finding also explains the rather slow kinetics of the intermolecular rearrangement processes and the failure to trap oxonium ion intermediates experimentally. QM/MM simulations and DFT calculations further indicated that the host guest system $\left[\mathbf{N H}_{4}{ }^{+} \subset \boldsymbol{o}-\mathbf{M e}_{2}-\right.$ 2.2.1] is indeed fluxional, i.e. that the experimentally proven intermolecular rearrangements are accompanied by intramolecular degenerate rearrangements.

\section{ASSOCIATED CONTENT}

Supporting Information. The Supporting Information is available free of charge on the ACS Publication website.

Experimental procedures, characterization and spectral data. Crystallographic data in CIF format. Detailed description of the simulations (MD and $\mathrm{QM} / \mathrm{MM}$ ) and DFT setups, Cartesian coordinates, details into the 2D umbrella sampling strategies, and more detailed DFT results and analysis and force field parameters used are given in the Supporting Information

\section{AUTHOR INFORMATION}

\section{Corresponding Author}

*max.vondelius@uni-ulm.de

* christof.jaeger@nottingham.ac.uk.

\section{Notes}

The authors declare no competing financial interest

\section{ACKNOWLEDGMENT}

This work was supported by the Deutsche Forschungsgemeinschaft (Emmy-Noether grant DE1830/2-1), an Experiment! grant of the VolkswagenStiftung and the DAAD (PhD fellowship to O. S.). We thank Dr. Elena Mena-Osteritz for crystal structure refinement, Mrs. Margit Lang for ICP-AES analyses and Dr. René-Chris Brachvogel for laying early foundations of this study. C. M. J. gratefully acknowledges access to the University of Nottingham's 
Augusta HPC service. The Croatian Science Foundation (project number: IP11-2013-8238) and the British Scholarship Trust are acknowledged for the additional financial support.

\section{REFERENCES}

(1) "A chemical species is said to be fluxional if it undergoes rapid degenerate rearrangements (generally detectable by methods which allow the observation of the behaviour of individual nuclei in a rearranged chemical species, e.g. NMR, X-ray). The term is also used to designate positional change among ligands of complex compounds and organometallics. In these cases, the change is not necessarily degenerate." IUPAC Compendium of Chemical Terminology, IUPAC, Research Triangle Park, NC.

(2) Cotton, F. A. Fluxional organometallic molecules. Acc. Chem. Res. 1968, 1, 257-265.

(3) Cotton, F. A. A Half-Century of Nonclassical Organometallic Chemistry: A Personal Perspective. Inorg. Chem. 2002, 41, 643-658.

(4) Schreiner, P. R. Does $\mathrm{CH}_{5}{ }^{+}$Have (a) "Structure?" A Tough Test for Experiment and Theory. Angew. Chem., Int. Ed. 2000, 39, 3239-3241.

(5) King, R. B. Fluxional Organometallic and Coordination Compounds, Wiley \& Sons, Chichester, UK, 2005, 1-39.

(6) McKee, M. L. Fluctional molecules. Interdiscip. Rev. Comput. Mol. Sci. 2011, 1, 943-951.

(7) Doering, W. v. E.; Roth, W. R. Thermal Rearrangements. Angew. Chem., Int. Ed. 1963, 2, 115-122.

(8) Ault, A. The Bullvalene Story. The Concept of Bullvalene, a Molecule That Has No Permanent Structure. J. Chem. Educ. 2001, 78, 924.

(9) Scholz, F.; Himmel, D.; Heinemann, F. W.; Schleyer, P. v. R.; Meyer, K.; Krossing, I. Crystal Structure Determination of the Nonclassical 2-Norbornyl Cation. Science 2013, 341, 62-64.

(10) Weimann, D. P.; Winkler, H. D. F.; Falenski, J. A.; Koksch, B.; Schalley, C. A. Highly dynamic motion of crown ethers along oligolysine peptide chains. Nat. Chem. 2009, 1, 573-577.

(11) Kovaříček, P.; Lehn, J.-M. Merging Constitutional and Motional Covalent Dynamics in Reversible Imine Formation and Exchange Reaction. J. Am. Chem. Soc. 2012, 134, 9446-9455.

(12) Kovaříček, P.; Lehn, J.-M. Directional Dynamic Covalent Motion of a Carbonyl Walker on a Polyamine Track. Chem. Eur. J. 2015, 21, 9380-9384.

(13) Campaña, A. G.; Carlone, A.; Chen, K.; Dryden, D. T. F.; Leigh, D. A.; Lewandowska, U.; Mullen, K. M. A Small Molecule that Walks Non-Directionally Along a Track without External Intervention. Angew. Chem., Int. Ed. 2012, 51, 5480-5483.

(14) Campaña, A. G.; Leigh, D. A.; Lewandowska, U. One Dimensional Random Walk of a Synthetic Small Molecule Toward a Thermodynamic Sink. J. Am. Chem. Soc. 2013, 135, 8639-8645.

(15) von Delius, M.; Leigh, D. A. Walking molecules. Chem. Soc. Rev. 2011, 40, 3656-3676.

(16) He, M.; Bode, J. W. Racemization as a stereochemical measure of dynamics and robustness in shape-shifting organic molecules. Proc. Natl. Acad. Sci. USA, 2011, 108, 14752-14756.

(17) Lippert, A. R.; Kaeobamrung, J.; Bode J. W. Synthesis of Oligosubstituted Bullvalones: Shapeshifting Molecules Under Basic Conditions. J. Am. Chem. Soc. 2006, 128, 14738-14739.

(18) Bismillah, A. N.; Sturala, J.; Chapin, B. M.; Yufit, D. S.; Hodgkinson, P.; McGonigal, P. R. Shape-selective crystallization of fluxional carbon cages Chem. Sci. 2018, 9, 8631-8636.

(19) Teichert, J. F.; Mazunin, D.; Bode, J. W. Chemical Sensing of Polyols with Shapeshifting Boronic Acids As a Self-Contained Sensor Array. J. Am. Chem. Soc. 2013, 135, 11314-11321.

(20) Larson, K. K.; He, M.; Teichert, J. F.; Naganawa, A.; Bode, J. W. Chemical sensing with shapeshifting organic molecules. Chem. Sci. 2012, 3, 1825-1828.

(21) Corbett, P. T.; Leclaire, J.; Vial, L.; West, K. R.; Wietor, J.-L.; Sanders, J. K. M.; Otto, S. Dynamic Combinatorial Chemistry. Chem. Rev. 2006, 106, 3652-3711.

(22) Jin, Y.; Yu, C.; Denman, R. J.; Zhang, W. Recent advances in dynamic covalent chemistry. Chem. Soc. Rev. 2013, 42, 6634. Synthesis and cation binding of macrocyclic polyethers possessing axially disposed secondary donor groups. J. Chem. Soc., Chem. Commun. 1980, 1053.

Herrmann, A. Dynamic combinatorial/covalent chemistry: a tool to read, generate and modulate the bioactivity of compounds and compound mixtures. Chem. Soc. Rev. 2014, 43, 1899-1933.

Li, J.; Nowak, P.; Otto, S. Dynamic Combinatorial Libraries: From Exploring Molecular Recognition to Systems Chemistry. $J$. Am. Chem. Soc. 2013, 135, 9222-9239.

Lehn, J.-M. Perspective in Chemistry - Aspects of Adaptive Chemistry and Materials. Angew. Chem., Int. Ed. 2015, 54, 3276-3289.

Lehn, J.-M. From supramolecular chemistry towards constitutional dynamic chemistry and adaptive chemistry. Chem. Soc. Rev. 2007, 36, 151-160.

Brachvogel, R.-C.; von Delius M. Orthoester exchange: a tripoda tool for dynamic covalent and systems chemistry. Chem. Sci. 2015, 6, 1399-1403.

Brachvogel, R.-C.; Hampel, F.; von Delius, M. Self-assembly of dynamic orthoester cryptates. Nat. Commun. 2015, 6, 7129.

Shyshov, O.; Brachvogel, R.-C.; Bachmann, T.; Srikantharajah, R.; Segets, D.; Hampel, F.; Puchta, R.; von Delius, M. Adaptive Behavior of Dynamic Orthoester Cryptands. Angew. Chem., Int. Ed. 2017, 56, 776-781.

von Delius, M. Small Is (also) Beautiful: Dynamic Covalent SelfAssembly of Cryptates. Synlett 2015, 27, 177-180.

Löw, H.; Mena-Osteritz, E.; von Delius, M. Self-assembled orthoester cryptands: orthoester scope, post-functionalization, kinetick locking and tunable degradation kinetics. Chem. Sci. 2018, 9, 4785-4793.

A reviewer of this article raised the justified concern that residual silver ions in our $\mathrm{NH}_{4} \mathrm{BArF}$ synthesized from $\mathrm{AgBArF}$ could be responsible for the observed reactivity. To address this concern, we carried out a number of experiments, which indicate very clearly that $\mathrm{Ag}^{+}$is not the catalyst for dynamic covalent exchange. For instance, $\mathrm{NH}_{4} \mathrm{BArF}$ synthesized from $\mathrm{NaBArF}$ gives rise to the same dynamic behaviour as that synthesized from AgBArF. For further details see section 1 in the SI.

Stock solutions of cryptands and diols were dried over $3 \AA$ molecular sieves. $\mathrm{NH}_{4} \mathrm{BArF}$ powder was dried overnight under high vacuum in a desiccator equipped with $\mathrm{P}_{2} \mathrm{O}_{5}$.

Severin, K. The Advantage of Being Virtual - Target Induced Adaptation and Selection in Dynamic Combinatorial Libraries. Chem. Eur. J. 2004, 10, 2565-2580.

Corbett, P. T.; Sanders, J. K. M.; Otto, S. Exploring the Relation between Amplification and Binding in Dynamic Combinatorial Libraries of Macrocyclic Synthetic Receptors in Water. Chem. Eur. J. 2008, 14, 2153-2166.

Ciaccia, M.; Pilati, S.; Cacciapaglia, R.; Mandolini, L.; Di Stefano, S. Effective catalysis of imine metathesis by means of fast transiminations between aromatic-aromatic or aromaticaliphatic amines. Org. Biomol. Chem. 2014, 12, 3282-3287.

Hibbert, D. B.; Thordarson, P. The death of the Job plot, transparency, open science and online tools, uncertainty estimation methods and other developments in supramolecular chemistry data analyses. Chem. Commun. 2016, 52, 12792-12805.

Istner, M.; Porezag, D.; Jungnickel G.; ElsnerJ.; Haugk M.; Frauenheim, T.; Suhai, S.; Seifert, G. Self-consistent-charge density-functional tight-binding method for simulations of complex materials properties. Phys. Rev. B 1998, 58, 7260-7268. Späth, A.; König, B. Molecular recognition of organic ammonium ions in solution using synthetic receptors. Beilstein J. Org. Chem. 2010, 6, 32

Graf, E.; Kintzinger, J. P.; Lehn, J.-M.; LeMoigne, J, Molecular recognition. Selective ammonium cryptates of synthetic receptor molecules possessing a tetrahedral recognition site. Am. Chem. Soc. 1982, 104, 6, 1672-1678.

Lazar, A. I.; Rohacova, J.; Nau, W. M. C Complexation-Induced $\mathrm{p} K_{\mathrm{a}}$ Shifts in the Ground and Excited States of Dyes as Well as Different Macrocyclic Hosts and Their Manifestation in Host-Retarded Excited-Dye Deprotonation. $J$. Phys. Chem. B 2017, 121, 50, 11390-11398. 
(43) Abbas, A. A.; Elwahy, A. H. M. Synthesis of C-Pivot Lariat Ethers. J. Heterocycl. Chem. 2009, 46, 1035-1079.

(44) Cragg, P. J.; Vahora, R. Supramolecular Chemistry, John Wiley \& Sons, Chichester, UK, 2012

(45) Cram, D. J. The Design of Molecular Hosts, Guests, and Their Complexis (Nobel Lecture). Angew. Chem., Int. Ed. 1988, 27, 1009-1020.

(46) Raynal, M.; Ballester, P.; Vidal-Ferran, A.; van Leeuwen, P. W. N. M. Supramolecular catalyses. Part 2: artificial enzyme mimics. Chem. Soc. Rev. 2014, 43, 1734-1787.

(47) Brown, C. J.; Toste, F. D.; Bergman, R. G.; Raymond, K. N Supramolecular Catalysis in Metal-Ligand Cluster Hosts. Chem. Rev. 2015, 115, 3012-3035.

(48) Leenders, S. H. A. M.; Gramage-Doria, R.; de Bruin, B.; Reek, J. N. H. Transition metal catalysis in confined spaces. Chem. Soc. Rev. 2015, 44, 433-448.

(49) Zarra, S.; Wood, D. M.; Roberts, D. A.; Nitschke, J. R. Molecular containers in complex chemical systems. Chem. Soc. Rev. 2014, $44,419-432$.
(50) Catti, L.; Zhang, Q.; Tiefenbacher, K. Self-Assembled Supramolecular Structures as Catalysts for Reactions Involving Cationic Transition States. Synthesis 2015, 48, 313-328.

(51) He, Q.-T.; Li, X.-P.; Chen, L.-F.; Zhang, L.; Wang, W.; Su, C.Y. Nanosized Coordination Cages Incorporating Multiple $\mathrm{Cu}(\mathrm{I})$ Reactive Sites: Host-Guest Modulated Catalytic Activity. ACS Catal. 2013, 3, 1-9.

(52) He, Q.-T.; Li, X.-P.; Liu, Y.; Yu, Z.-Q.; Wang, W.; Su, C.-Y. Copper(I) Cubooctahedral Coordination Cages: Host-Guest Dependent Redox Activity. Angew. Chem., Int. Ed. 2009, 48, 6156-6159.

(53) Jones, F. J.; Kilner, C. A.; Halcrow, M. A. A Cobalt Metallacrown Anion Host with Guest-Dependent Redox Activity. Chem. Eur. J. 2009, 15, 4667-4675.

(54) Ratjen, L.; Vantomme, G.; Lehn, J.-M. Strain-Induced Reactivity in the Dynamic Covalent Chemistry of Macrocyclic Imines. Chem. Eur. J. 2015, 21, 10070-10081. 
Insert Table of Contents artwork here

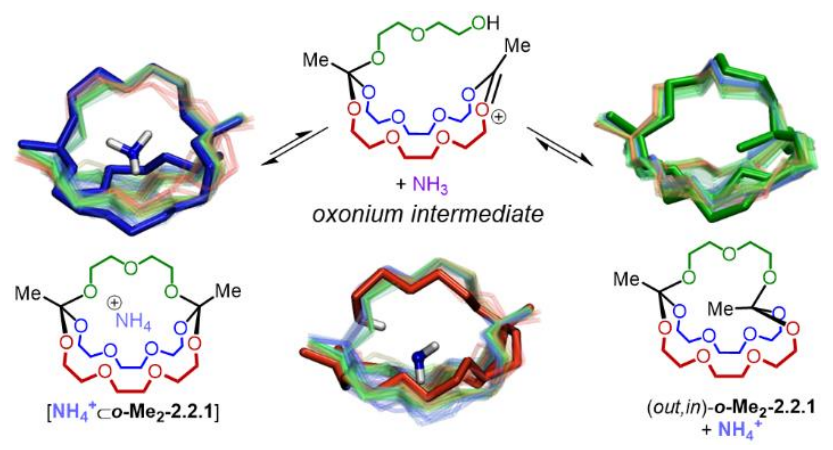

